\title{
Amelioration of Chilling Injury in Phaseolus vulgaris L. by GLK-8903
}

\author{
Agnes A. Flores-Nimedez ${ }^{1}$ and Paul H. Li \\ Laboratory of Plant Hardiness, Department of Horticultural Science, University of Minnesota, St. Paul, \\ MN 55108
}

\author{
Charles C. Shin ${ }^{2}$ \\ Great Lakes Chemical Corporation, West Lafayette, IN 47906
}

\begin{abstract}
Additional index words. deplasmolysis, electrolyte leakage, malondialdehyde, membrane permeability, osmotic potential, plasmolysis, proline

Abstract. GLK-8903, an experimental product whose main ingredient is produced by hydrogenation of a primary alcohol extracted from plants, showed significant potential in protecting bean (Phaseolus vulgaris L.) plants from chilling injury. The GLK-8903 protection mechanism was assessed by examining several physiological and biochemical responses. The decline in leaf water potential and the increase in osmotic potential caused by chilling exposure to 4C (day/night) were minimized by the application of GLK-8903. Chilling causes an increase in electrolyte leakage, an indication of chilling injury of the plasma membrane. Increased electrolyte leakage was reduced significantly in the GLK-8903-treated plants during chilling. This minimized leakage may be due to less damage of the plasma membrane. Plasmolysis and deplasmolysis studies of the epidermal cells suggest that GLK-8903 is able to reduce the plasma membrane perturbation in the chilling environment, as evident by: 1) the lower permeability coefficient to urea at $4 \mathrm{C}$, and 2) the swelling of protoplasts in the cells of untreated tissues after chilling exposure with no swelling of the protoplast being observed in the GLK-8903-treated cells. Malondialdehyde (MDA), a product of lipid peroxidation, increased more in untreated controls than in treated plants exposed to 4C. Plasma membrane ATPase activity decreased less in GLK-8903-treated plants than in untreated controls after 3 days at 4C. The mechanism of GLK-8903-alleviated chilling injury is discussed.
\end{abstract}

Temperatures between 0 and 10C are a major factor limiting growth and development of chilling-sensitive plant species (Lyons et al., 1979). Resultant growth inhibition reduces crop yield; bean production was reduced by $34 \%$ at low soil temperature (Wierenga and Hagan, 1966). Different strategies have been investigated by plant breeders and plant physiologists attempting to minimize the low temperature injury in chilling-sensitive crops. Alleviation of chilling injury (CI) by the application of chemicals have been reported. Mefluidide has been reported to reduce $\mathrm{CI}$ in maize (Zea mays L.) and rice (Oryza sativa L.) (Tseng et al., 1986; Zhang et al., 1987). Triazoles have been shown to increase chilling tolerance in plants (Fletcher and Hofstra, 1988; Whitaker and Wang, 1987). Chilling tolerance can be improved by abscisic acid (ABA) (Rikin et al., 1979; Kin and Li, 1992). Flores et al. (1988) and Flores and Dorffling ( 1990) reported that terpenoid analogues of ABA increased chilling tolerance in cucumber (Cucumis sativus L.) and tomato (Lycopersicon esculentum Mill.) plants. Increased chilling tolerance in rice by ABA analogues has also been reported (Flores-Nimedez et al., 1990a, 1990b). We report here another chemical, GLK-8903, that shows potential for protecting bean plants from CI.

\section{Materials and Methods}

Plant material. Seeds of 'Bush Blue Lake 47' bean (Asgrow Seed Co., Kalamazoo, Mich.) were sown in a mix containing 2

Received for publication 8 Sept. 1992. Accepted for publication 19 Jan. 1993. Scientific Journal Series Paper no. 20127 of the Minnesota Agricultural Experiment Station, St. Paul, MN 55108. We thank Ed and Ok Young Stadelmann for providing the facilities for membrane permeability experiments, A.H. (Bud) Markhart III for help in water relations measurements, Ed Nater for the use of a double-beam spectrophotometer, David W. Davis for the critical reading, and the many others from various countries who helped. This research was supported in part by a gift from the Great Lakes Chemical Corp., West Lafayette, Ind.

${ }^{1}$ Current address — c/o Jun Nimedez, IRRI, P.O. Box 933, Manila, Philippines.

${ }^{2}$ To whom inquiries on GLK-8903 information should be addressed. peatmoss : 1 soil : 1 prolite, (v/v) in 1.5-liter pots. Seedlings were raised in a growth chamber at a regime of 25/22C (day/night), 14-h photoperiod with photon flux density (PFD) of $300 \mu \mathrm{mol} \cdot \mathrm{m}^{-2} \cdot \mathrm{s}^{-1}$ and $75 \%$ RH. Fourteen- and 20-day-old plants of uniform height were selected and thinned to three plants per pot.

$G L K-8903$. GLK-8903 is an experimental product of the Great Lakes Chemical Corp., West Lafayette, Ind. Its main active ingredient is produced by hydrogenation of a primary alcohol extracted from corn stalks, sugar cane, and other biomass. It is a colorless, high-boiling-point primary alcohol containing a heterocyclic ring. Due to its cyclic ether and alcohol structure, it has some unique solvent properties, such as low volatility, easy absorbability, high membrane penetrability, and limitless solubility in water, in addition to its ability to form multiple hydrogen bonds and the ability to dissolve electrolyte and non-electrolyte solutes.

Treatment with GLK-8903. Five milliliters of GLK-8903 was diluted to 1 liter with distilled water containing $0.05 \%$ Tween-20 to a concentration of $0.5 \%$ of GLK-8903. The aqueous solution was sprayed on the plants until leaves were completely wet. When the leaves were dry (after $3 \mathrm{~h}$ ), the plants were returned to the growth chamber. Control plants were sprayed with the water and Tween-20 solution containing no GLK-8903.

Chilling treatment. Plants were transferred to a room at $4 / 4 \mathrm{C}$ (day/night) and a 14-h photoperiod $24 \mathrm{~h}$ after having been sprayed. A set of plants was removed from the cold room to the growth chamber at the end of chilling (day 1 , day 2 , and day 3 ) for recovery observation.

Measurements of chilling injury. Symptoms of CI were recorded by visual observation and by monitoring plant water relations; i.e., leaf fresh weight loss and changes in water potential and osmotic potential. The effect of GLK-8903 on membrane integrity and membrane permeability of chilled cells was measured by electrical conductivity and by plasmolysis and deplasmolysis, respectively.

Water potential. Primary leaves were removed from chilled 
plants at the end of chilling (day 1, day 2, and day 3); the cut leaf petiole was wrapped in a plastic bag to minimize the leaf water loss; and water potential was measured immediately by using a pressure bomb (Soil Moisture Equipment Corp., Santa Barbara, Calif.).

Osmotic potential. Three primary leaves were removed from chilled plants at the end of chilling (day 1, day 2, and day 3), placed in a plastic bag, and cell sap was pressed by a laboratory-made cylindrical metal device. Aliquots of $0.2 \mathrm{ml}$ of cell sap were pipetted into 1.5-ml disposable Eppendorf vials (No.72.690.500, $39 \times 10-\mathrm{mm}$, Sarstedt, Germany), and centrifuged for $5 \mathrm{~min}$ at 14,000× $g$ (Eppendorf Centrifuge 5414). Eight microliters of sap were pipetted onto a filter paper disc and osmolarity was read using a Wescor 5100 C Vapor Pressure Osmometer (Wescor, Logan, Utah). Solute concentration was determined by freezing-point depression.

Electrolyte leakage. Five 1.2-cm-diameter leaf discs from primary leaves collected at the end of chilling were immersed in a plastic vial containing $10 \mathrm{ml}$ of double-distilled water. The leakage of electrolytes was measured according to the procedure of Palta et al. (1977) using a WESCAN Conductivity Meter (WESCAN Instruments, Inc. Santa Barbara, Calif.). Conductivity was expressed as the percentage of total electrolyte of the same discs after being killed by a freeze-thaw cycle.

Urea permeability. The plasmometric method (Stadelmann, 1966) was used to study the passive transport or permeation of urea through the lipid portion of the plasma membrane of epidermal cells. Epidermal sections one to three cells thick and $0.5 \mathrm{~cm}$ in length were cut from the primary leaf midrib, immersed in $10 \mathrm{ml}$ of defined solution ( $3.5 \mathrm{mM} \mathrm{CaCl}_{2}$ plus $25 \mathrm{mM} \mathrm{KCl}$ ), and connected to an aspirator for 2 to $3 \mathrm{~min}$ until bubbling occurred. The cells were plasmolyzed by immersing the tissues in a 0.2 osmol $\mathrm{KCl} /$ $\mathrm{CaCl}_{2}$ salt mixture ( $1 \mathrm{M} \mathrm{KCl}: 1 \mathrm{M} \mathrm{CaCl}_{2}, 4: 6$ ratio), then progressively in $0.4,0.6$, and $0.7 \mathrm{osmol}$ each for $20 \mathrm{~min}$ (initial plasmolysis). Tissues were then transferred to a perfusion chamber, which was placed on a microscope. The chamber was sealed with a cover slip brushed on the rim with Vaseline. Final osmotic equilibrium was achieved by passing the 0.7-osmol salt mixture for $30 \mathrm{~min}$ through the chamber. Then the external solution was changed from 0.7 osmol salt mixture to 0.7 osmol urea. The time of initial contact of urea with tissue was set as zero time. The protoplasts were deplasmolyzed in response to passive uptake of urea. The change in protoplast length was measured at appropriate time intervals using an eyepiece micrometer. Permeability coefficients $\left(\mathrm{K}_{\mathrm{S}}\right)$ were calculated as described by Stadelmann (1968, 1989).

Plasma membrane ATPase activity. ATPase activity was measured by coupling ATP hydrolysis to the oxidation of NADH using the linked enzyme assay according to Fricker and Willmer (1987) and Auffret and Hanke (1981). One gram (fresh weight) of leaf tissue (three primary leaves per sample) was frozen with liquid nitrogen and homogenized in a precooled mortar and pestle with $5 \mathrm{ml} \mathrm{Mes-KOH}$ buffer and $5 \mathrm{ml}$ dithiothreitol. The mixture was then transferred to centrifuge tubes in an icebox and centrifuged. The assay medium contained $15 \mathrm{ml}$ Mes-KOH buffer $(\mathrm{pH}$ 6.5) with $3 \mathrm{mM} \mathrm{MgCl}, 2 \mathrm{mM}$ phosphoenolpyruvate (PEP), $0.33 \mathrm{mM}$ $\mathrm{NADH}, 3 \mathrm{~mm}$ dithiothreitol, $0.01 \%$ bovine serum albumin, 10 units of pyruvate kinase, 10 units of lactate dehydrogenase (Sigma, St. Louis), and Triton X-100 ( $0.005 \%$ by volume). Ammonium molybdate $(0.2 \mathrm{mM})$ and sodium azide $(0.02 \mathrm{mM})$ were included in the assay medium to inhibit the activities of nonspecific phosphatases and chloroplastic and mitochondrial ATPases, respectively. The reaction was started by the addition of ATP (final concentration, $3 \mathrm{mM}$ ). Measurements were made using a double- beam spectrophotometer. Vanadate-sensitive ATPase activity was measured as the difference in rates of NADH oxidation in the presence and absence of $0.02 \mathrm{mM}$ sodium vanadate. Assays were carried out in triplicates per treatment, each for $30 \mathrm{~min}$, during which $P_{i}$ release was linear. Chlorophyll concentration was measured by using $1 \mathrm{ml}$ of the extract diluted with $4 \mathrm{ml}$ of acetone and centrifuged at $14,000 \times g$ for $5 \mathrm{~min}$. The filtrate was pipetted in another test tube and optical density was read at 663,645, and 720 $\mathrm{nm}$.

Determination of lipid peroxidation. The level of lipidperoxidation was measured in terms of the accumulation of malondialdehyde (MDA), a product of lipid peroxidation. MDA was determined by the reaction of thiobarbituric acid (TBA), as described by Dhindsa et al. (1981) and Heath and Packer (1968), with minor modifications. Five primary leaves were removed from plants. The tissues $(0.25 \mathrm{~g}$ fresh weight) were homogenized with mortar and pestle in $5 \mathrm{ml} 0.1 \%$ trichloroacetic acid (TCA). Samples were centrifuged at $10,000 \times \mathrm{g}$ for $5 \mathrm{~min}$. To $1 \mathrm{ml}$ of the supernatant, $4 \mathrm{ml}$ of $20 \%$ TCA, containing $0.5 \%$ TBA, was added. The mixture was heated at $95 \mathrm{C}$ for $30 \mathrm{~min}$, then cooled immediately in ice. The mixture was centrifuged at $10,000 \times g$ for $10 \mathrm{~min}$. The absorbance of the supernatant was read at 532 and $600 \mathrm{~nm}$.

Determination of proline. Proline content was measured according to the procedure of Bates et al. (1973). Three primary leaves $(1.0 \mathrm{~g}$ fresh weight) were collected and frozen in liquid nitrogen, homogenized in $20 \mathrm{ml}$ sulfosalicylic acid (3\%), and shaken overnight at $3 \mathrm{C}$. The extract was filtered and the filtrate was used for the reaction with ninhydrin.

\section{Results and Discussion}

The GLK-8903 study for plant chilling protection was initiated in 1989. Most experiments were conducted in the greenhouse and growth chambers. Chilling protection was evaluated mostly with young plants of dicots, including 'Sunny' tomato, bell pepper (Capsicum annum L., cv Ma Belle), and 'BBL 47' common bean. By examining the poststress growth and development, we found that plants treated with GLK-8903 had better recovery from CI and flowered earlier, resulting in earlier harvest and higher yield with better quality as compared to the chilled but untreated controls. In a nonchilled environment, the treatment (foliar spray with $0.5 \%$ to $1 \%$ GLK-8903) did not affect growth and development as cornpared to that of the untreated controls.

For a greater understanding of how GLK-8903 protects plants from CI, we examined several physiological and biochemical responses that are known to be involved in chilling resistance/ injury. We chose the common bean as a test model because: 1) it is chilling-sensitive, with visual signs of injury in leaf wilting; and 2) it has a relatively short life cycle, thus using less time for a complete growth and development observation.

Chilling injury. Exposure of bean plants to 4C led to the development of CI characterized by leaf wilting (Fig. 1). The longer the period of chilling exposure, the greater the degree of wilting, as shown after 2 and 3 days at 4C (Fig. 1 B and C). Controls exposed to $4 \mathrm{C}$ for 2 or 3 days showed severely wilted leaves. In contrast, plants sprayed with GLK-8903 before chilling retained leaf turgor during chilling and after recovery at $25 \mathrm{C}$. The effect of GLK-8903 on chilling protection can be seen even after 17 and 16 days growth at 25C (Fig. $1 \mathrm{D}$ and E). Although there was some recovery from $\mathrm{CI}$ in control plants, flower bud formation and flowering were delayed as compared to GLK-8903-treated plants.

Water relations. Leaf wilting (Fig. 1) was the visible sign of CI, a result of leaf water content reduction. Fresh weight of primary 

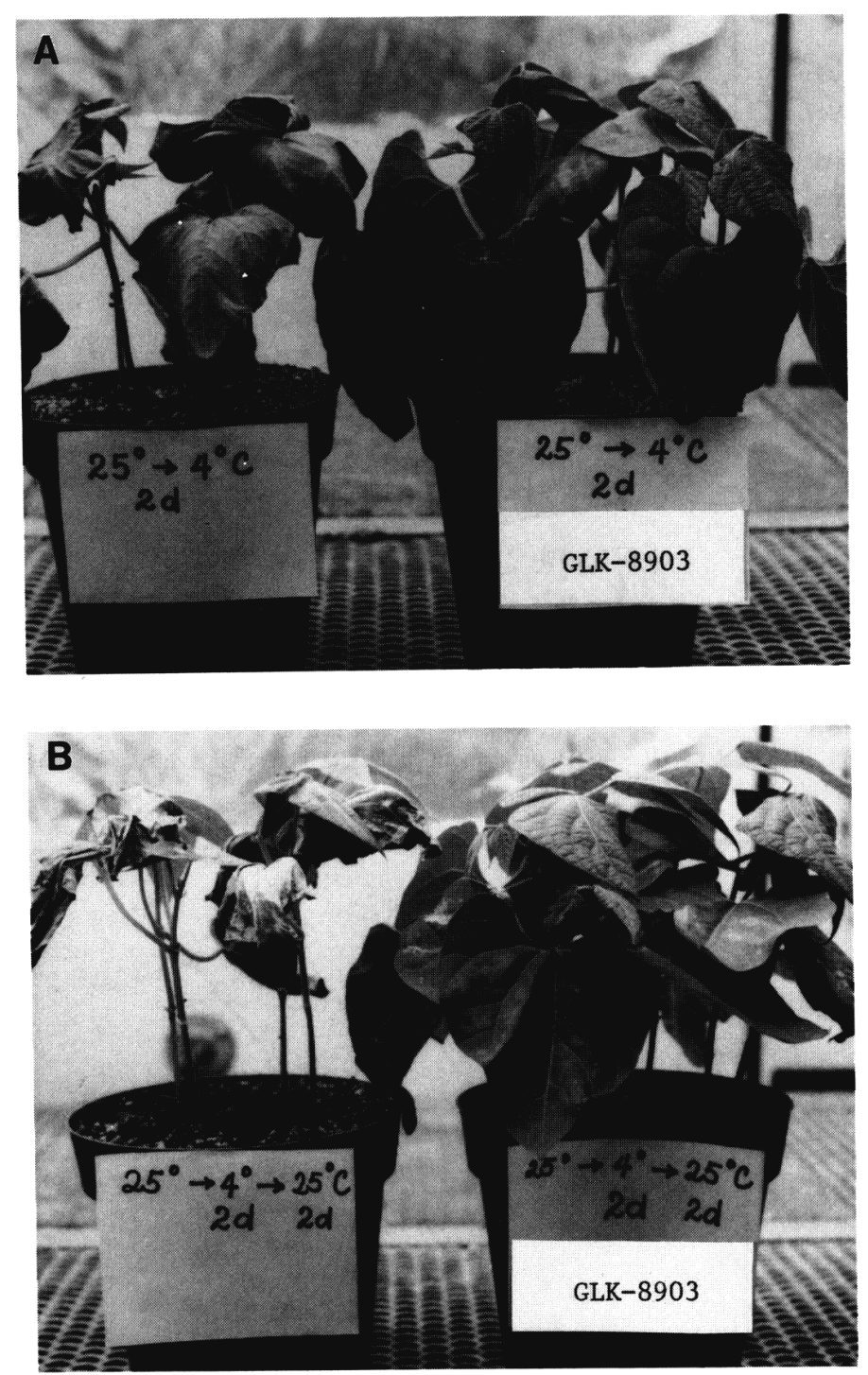

Fig. 1. Leaf wilting as a symptom of chilling injury was more pronounced in the untreated controls than in GLK-8903-treated plants. (A) Plant appearance immediately after 2 days (2d) of exposure to $4 \mathrm{C}$. Untreated controls became severely wilted, whereas treated plants showed less wilting. (B) Appearance of treated and control plants after 2 days at $4 \mathrm{C}$ followed by 2 days at $25 \mathrm{C}$. Treated plants regained turgor fully, while leaves of untreated controls were dessicated and dried. (C) Appearance of treated and untreated plants after 3 days (3d) at 4C followed by 1 day (1d) at 25C. (D) and (E) Poststress growth and development of treated and untreated plants. Plants were grown for 17 days (17d) (D) and 16 days (16d) (E) at $25 \mathrm{C}$ after $2 \mathrm{~d}$ and $3 \mathrm{~d}$ chilling exposure at $4 \mathrm{C}$, respectively. Untreated control plants had resumed growth, while treated plants had advanced to the flowering stage.

leaves declined during chilling. The decline, however, was less in the GLK-8903-treated plants than in untreated controls (Fig. 2). GLK-8903-treated plants lost only $1.2 \%$, compared to $31.5 \%$ in the control plants after 1 day at $4 \mathrm{C}$; losses after 3 days at $4 \mathrm{C}$ were $28.9 \%$ and $46.3 \%$ in treated and control plants, respectively. Leaf water potential was maintained at a constant level, attaining values between -0.46 and $-0.48 \mathrm{MPa}$ at $25 \mathrm{C}$, but declined when plants were transferred to $4 \mathrm{C}$, and continued to decrease when chilling was prolonged (Fig. 3). However, the decline was less (-0.69 MPa) in plants treated with GLK-8903, compared to the controls with $-0.78 \mathrm{MPa}$ after 3 days at $4 \mathrm{C}$. We observed no difference in leaf transpiration between GLK-8903-treated and control plants during chilling exposure (data not shown). Osmolarity, however, increased 1.44-fold during chilling of control as compared to
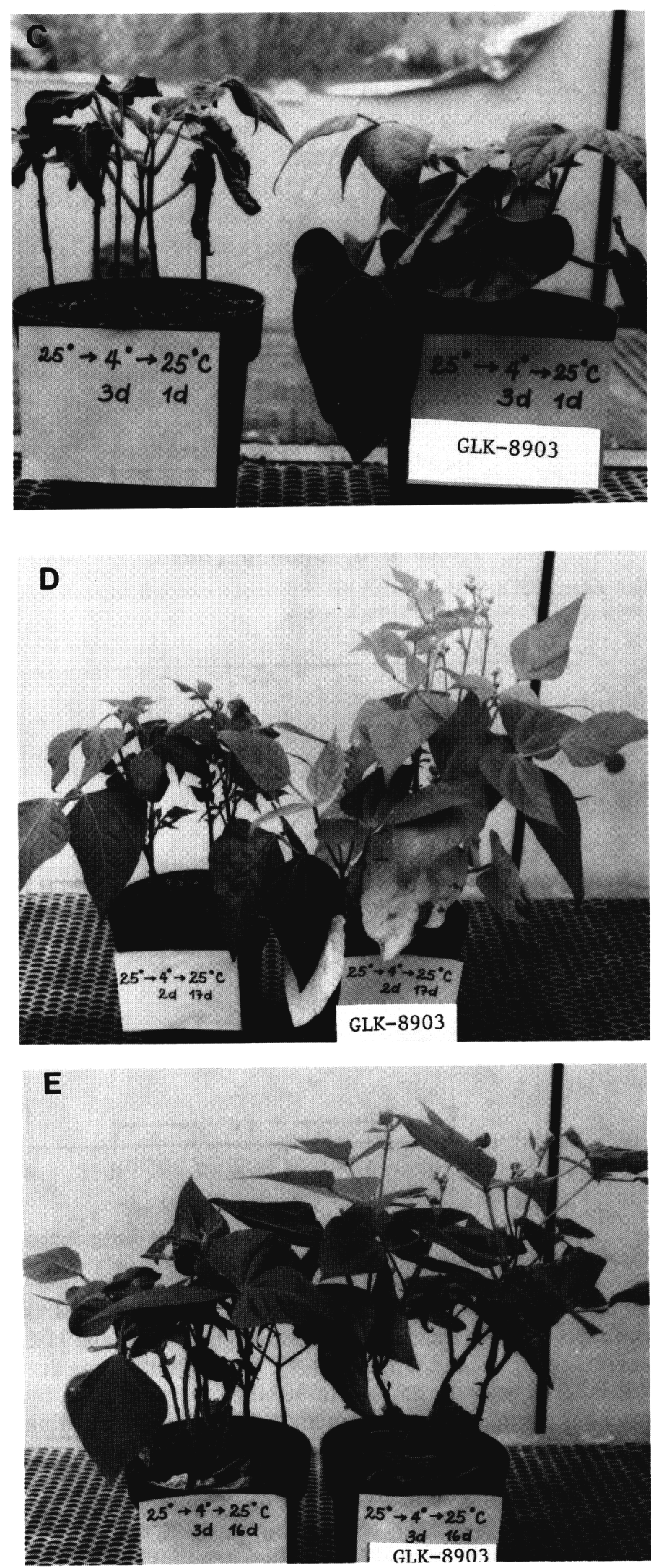

treated plants (Fig. 4).

Membrane stability. GLK-8903 affected not only the leaf water relations, but also plasma membrane integrity and permeability. Ion leakage (or electrical conductivity) from untreated controls and treated leaves was maintained relatively constant between 


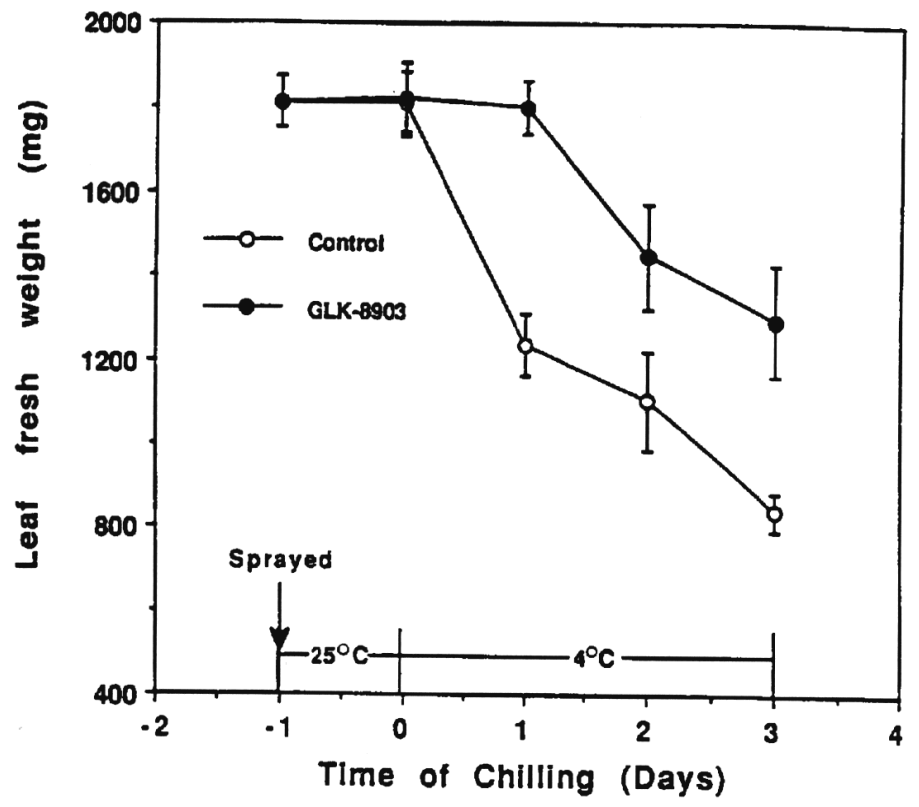

Fig. 2. Effect of GLK-8903 on primary leaf fresh weight before and during chilling exposure at $4 \mathrm{C}$. Mean \pm SE of 10 replications.

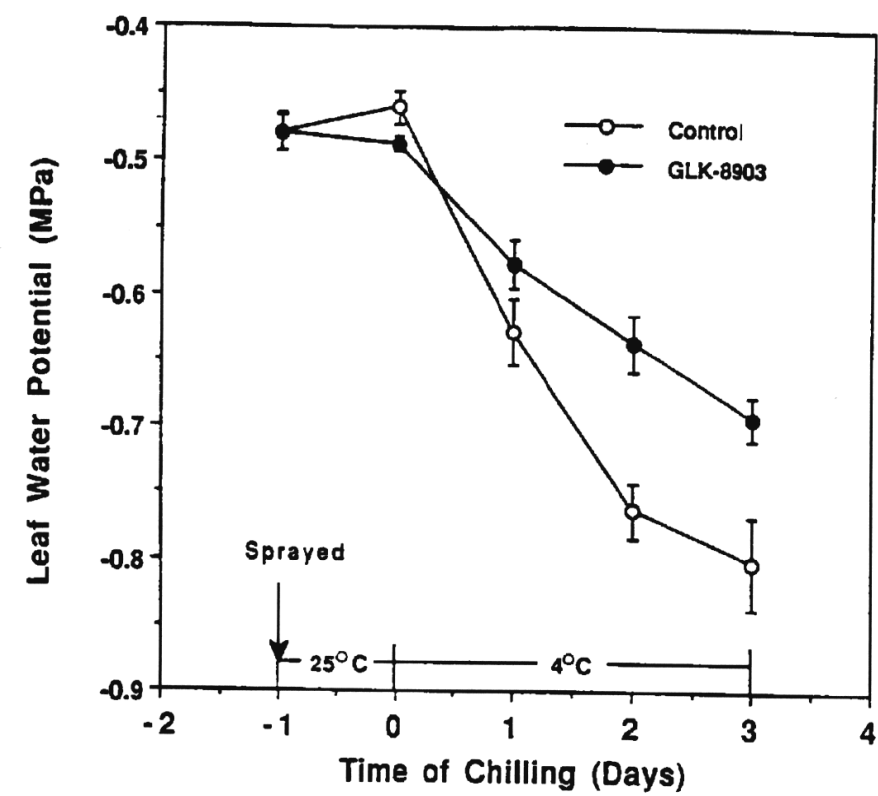

Fig. 3. Effect of GLK-8903 on leaf water potential before and during chilling exposure at $4 \mathrm{C}$. Mean $\pm \mathrm{SE}$ of six replications.

$12 \%$ and $16 \%$ at $25 \mathrm{C}$ (Fig. 5). Ion leakage increased when plants were exposed to $4 \mathrm{C}$, and reached $\approx 22 \%$ in treated plants and $71 \%$ in untreated controls after 3 days at $4 \mathrm{C}$. These results imply that GLK-8903 appears to be able to stabilize the membrane by preventing the reduction of membrane ATPase activity during chilling, as suggested by Palta and Li (1980).

Data from plasmolysis and deplasmolysis (Fig. 6) suggest that GLK-8903 stabilizes plasma membrane permeability at 4C. After 3 days at $4 \mathrm{C}, \mathrm{K}_{\mathrm{s}}$ was $1.965 \times 10^{-4} \mathrm{~cm} \cdot \mathrm{s}^{-1}$ in GLK-8903-treated plants vs 4.003 in the controls. When tissues were plasmolyzed and deplasmolized after 3 days at 4C, cells of control plants showed swelling protoplasts and the development of caps at the ends (Fig. 7A), as illustrated by the arrows. The swelling could be a consequence of injury, wherein tonoplast permeability for $\mathrm{K}^{+}$increased. An increase in permeability may have led to the rapid migration of ions from the vacuole into the protoplasm, resulting in colloidal

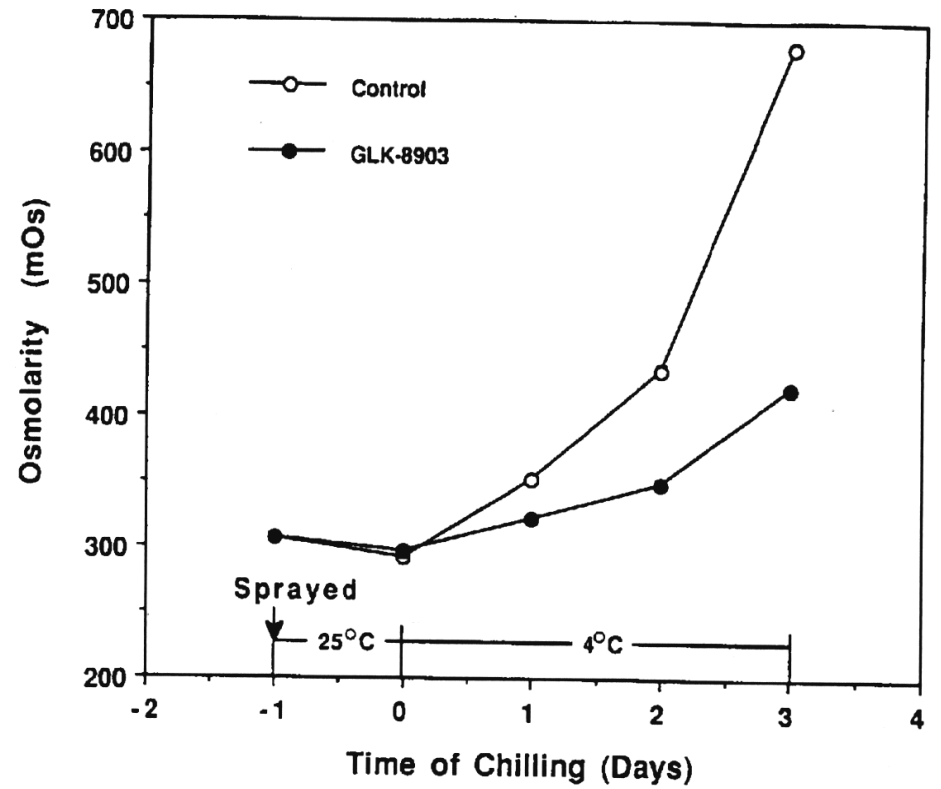

Fig. 4. Effect of GLK-8903 on osmotic potential before and during chilling exposure to $4 \mathrm{C}$. Mean $\pm \mathrm{SE}$ of six replications.

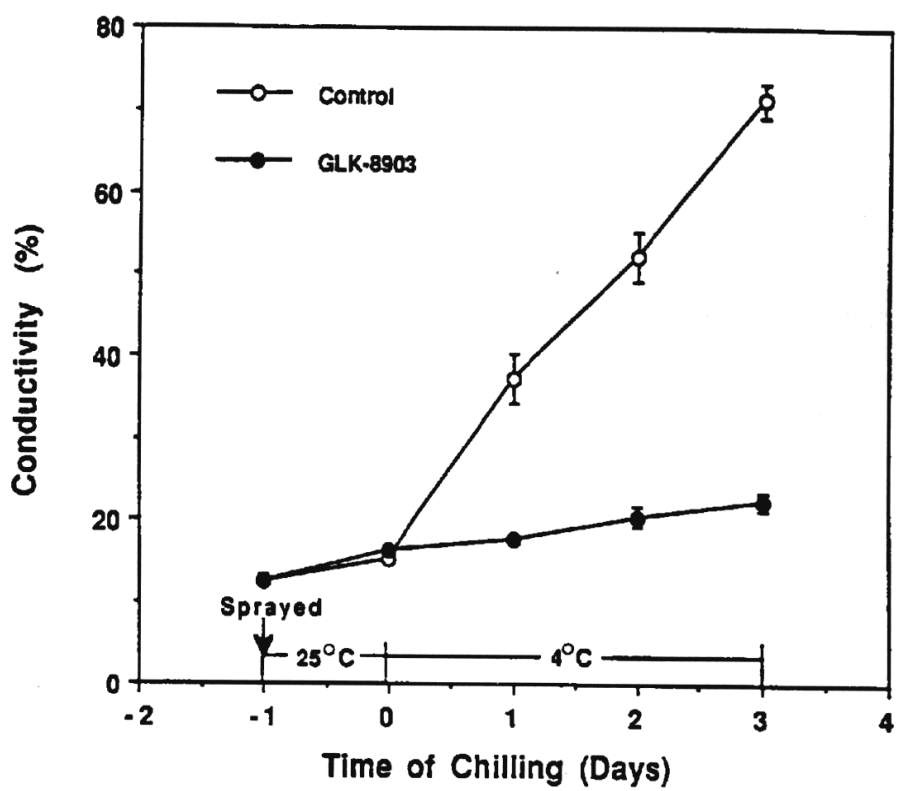

Fig. 5. Electrolyte leakages in untreated controls and GLK-8903 treated plants before and during chilling exposure to $4 \mathrm{C}$

swelling by water uptake. Such an increase in water content would cause a decline in protoplasm viscosity, thus leading to confinement of the swollen plasma to the protoplast ends and cap formation (Stadelmann, 1966). Protoplast swelling and cap development were seldom seen in plants treated with GLK-8903 after 3 days at 4C (Fig. 7B). Cells deplasmolyzed gradually in the GLK-8903treated plants, while deplasmolysis was faster in the control. Permeability of the plasma membrane to urea depends on maintenance of the lipid portion of the membrane and permeability increases in damaged membranes (Lee-Stadelmann, 1991). GLK8903 seems to exert a protective role on the plasma membrane by stabilizing the lipid portion during chilling exposure.

Exposure of bean plants to $4 \mathrm{C}$ led to $\mathrm{CI}$, resulting in increased ion leakage (Fig. 5). Increased leakage has been reported to be a consequence of membrane damage caused by increased lipid peroxidation (Dhindsa et al., 1981). Thus, we investigated the level of lipid peroxidation in chilled bean plants in terms of malondial- 


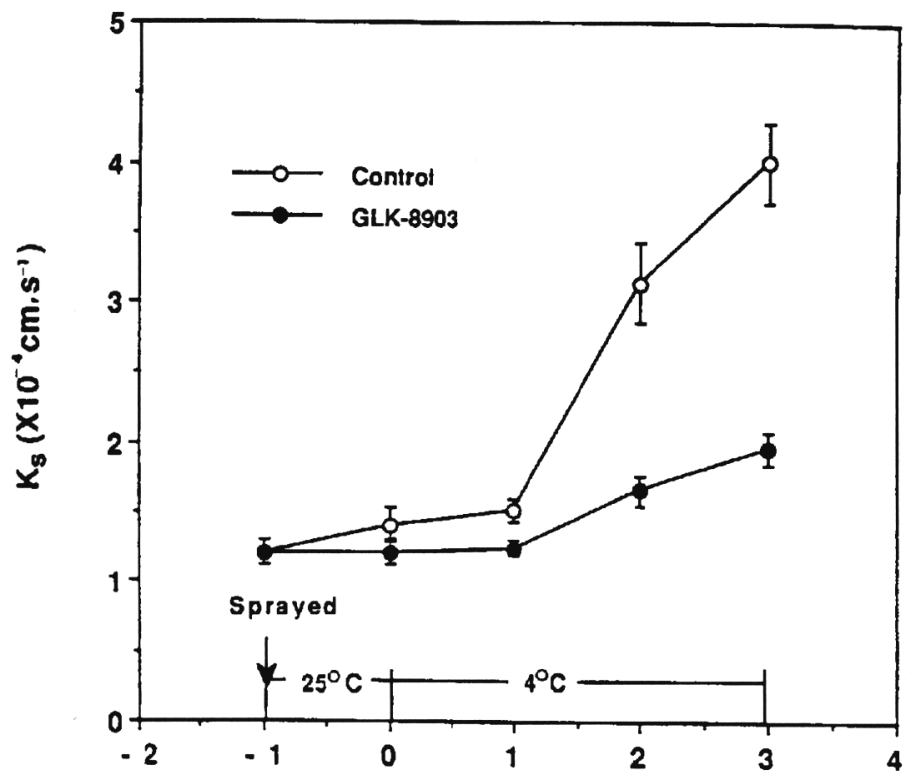

Time of Chilling (Days)

Fig. 6. Changes in the membrane permeability coefficient $\left(\mathrm{K}_{\mathrm{s}}\right)$ during chilling at $4 \mathrm{C}$ in GLK-8903-treated and nontreated plants. Mean \pm SE of eight replications.
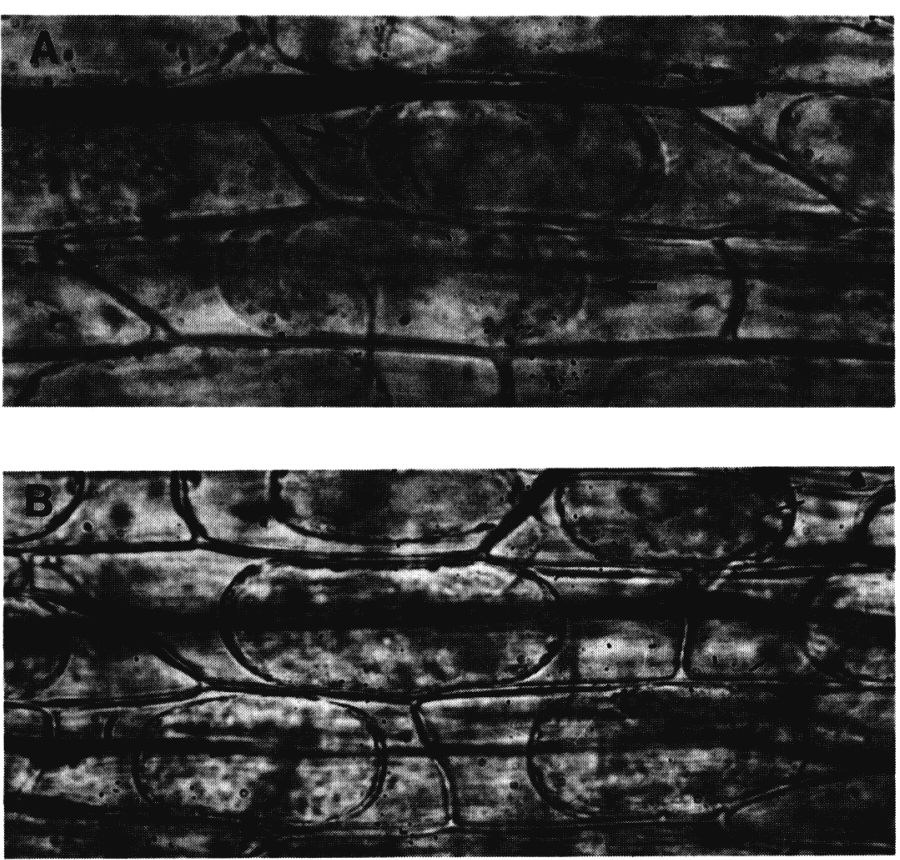

Fig. 7. (A) Protoplast swelling and development of caps (arrow) at the protoplast ends in untreated controls after 3 days at 4C. (B) Cells of GLK-8903-treated plants showed no swelling and caps after 3 days at $4 \mathrm{C}$.

dehyde (MDA), a decomposition product of unsaturated fatty acids. The MDA bleaches endogenous chlorophyll and consumes oxygen (Heath and Packer, 1968). The amount of MDA was $\approx 20$ nmol (per gram fresh weight of leaf tissue) in bean plants grown at 25C. There was no difference in MDA content between GLK8903-treated and untreated plants at 25C (Fig. 8). However, upon exposure to $4 \mathrm{C}$, MDA increased after 1 day, and continued to increase, attaining 55 and $30 \mathrm{nmol}$ after 3 days at $4 \mathrm{C}$ in untreated and treated plants, respectively. Although MDA increased in GLK-8903-treated plants during chilling, the level was significantly below that of the untreated controls (Fig. 8). The MDA data suggest that GLK-8903 is able to alleviate the chilling-induced lipid peroxidation. Lipid peroxidation involves the production of

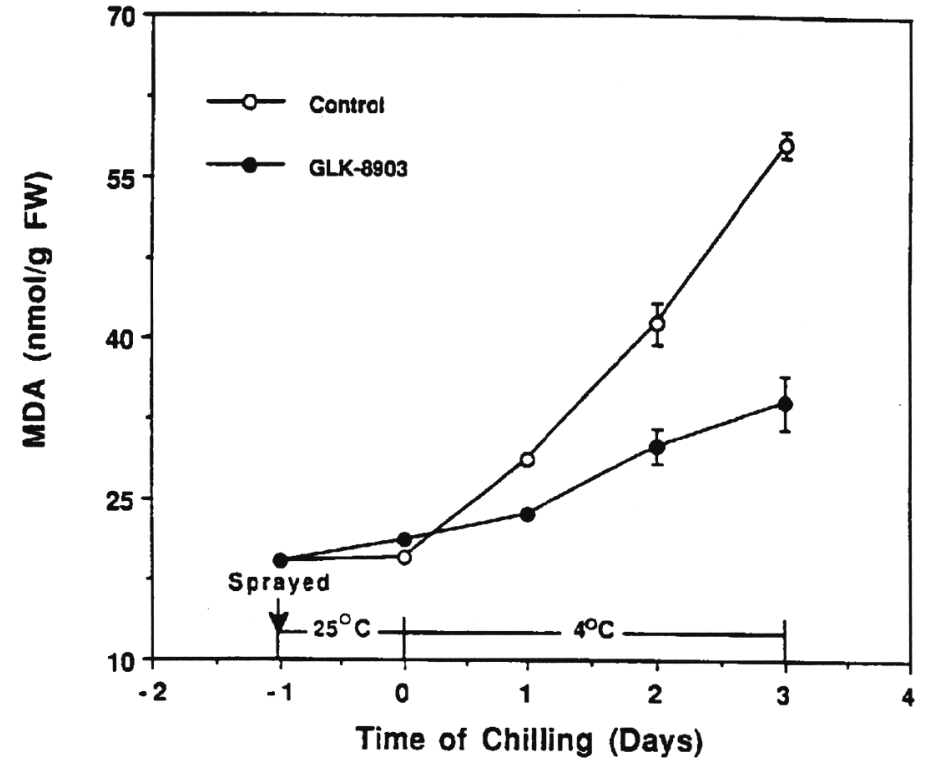

Fig. 8. Changes in malondialdehyde (MDA) level at 25C and 4C in GLK-8903treated and untreated plants. Mean \pm SE of five replications.

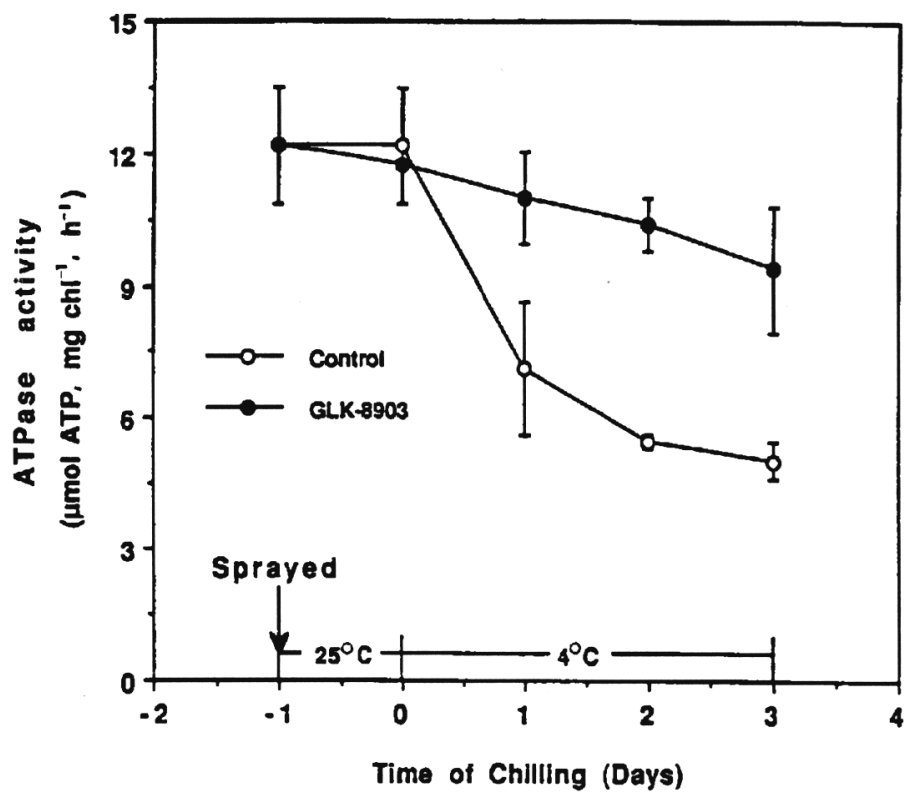

Fig. 9. Changes in ATPase activity at $25 \mathrm{C}$ and $4 \mathrm{C}$ in GLK-8903-treated and untreated plants. Mean \pm SE of three replications.

superoxide radical $\left(\mathrm{O}_{2}\right)$ (Dhindsa and Matowe, 1981) and, consequently, to hydrogen peroxide. The presence of $\mathrm{O}_{2}$ and $\mathrm{H}_{2} \mathrm{O}_{2}$ may cause breakdown (damage) of membrane phospholipids (Mayak et al., 1983) and, hence, result in a high $\mathrm{K}_{\mathrm{S}}$, as shown in Fig. 6, to urea.

A high level of ion leakage due to low-temperature stress is known to be coupled with reduced activity of membrane ATPase (Uemura and Yoshida, 1986). Therefore, we investigated whether GLK-8903 treatment affects plasma membrane ATPase activity in bean plants when exposed to 4C. Membrane ATPase activity decreased markedly at $4 \mathrm{C}$ in untreated controls, from a prechilling level of $12 \mu \mathrm{mol}$ ATP (mg Chl per h) to $7 \mu \mathrm{mol}$ after 1 day at $4 \mathrm{C}$ (Fig. 9). As chilling exposure was prolonged, activity continued to decline, to a level of $5 \mu \mathrm{mol}$ after 3 days at $4 \mathrm{C}$. The decreases in ATPase activity were significantly lower in GLK-8903-treated plants, from a prechilling level of 12 to about $11 \mu \mathrm{mol}$ after 1 day at $4 \mathrm{C}$, and to about $9 \mu \mathrm{mol}$ after 3 days at $4 \mathrm{C}$ (Fig. 9). Uemura and 


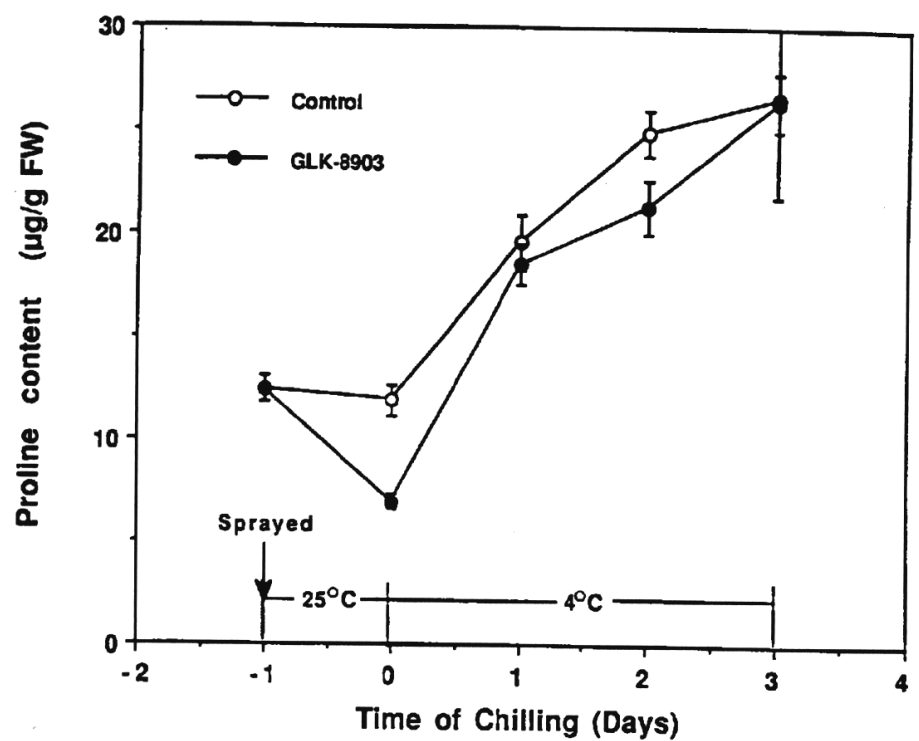

Fig. 10. Changes in proline content at 25C and 4C in GLK-8903-treated and untreated plants. Mean \pm SE of five replications.

Yoshida (1986) suggested that the ATPase was partially damaged in the low temperature environment as a result of alterations of membrane lipids and/or membrane proteins. Substantially higher membrane perturbation in untreated controls than in GLK-8903 treated plants during chilling is supported by the observations of more accumulated MDA (Fig. 8), swelling of protoplasts (Fig. 7), higher Ks to urea (Fig. 6), and more ion leakage (Fig. 5) in untreated controls.

Proline. The possibility that proline is involved in chilling tolerance is supported by the following evidence: 1) plants accumulate proline quickly when exposed to low temperature stress (Chu et al., 1987); 2) addition of the proline to the culture medium increases the chilling tolerance of maize callus and suspension cultured cells (Duncan and Widholm, 1978, 1990); and 3) chemical agents that increase proline content increase chilling tolerance (Duncan and Widholm, 1987; Flores et al., 1988). We examined whether GLK-8903 treatment increases proline content in bean plants before and during chilling. Proline decreased from a pretreatment level of $12.1 \mu \mathrm{g}$ (per gram fresh weight) to $5.5 \mu \mathrm{g}$ after GLK-8903-treated plants were held 1 day at 25C (Fig. 10). Proline increased in both treated and untreated plants during chilling, reaching a high level of about $26.5 \mu \mathrm{g}$ after 3 days at $4 \mathrm{C}$. We concluded that protection of GLK-8903 is unlikely to occur via differential increase in proline content.

Our data suggest that GLK-8903 may prevent lipid peroxidation, resulting in less plasma membrane perturbation in a chilling environment. Low water potential, low ion leakage, low permeability coefficient to urea, absence of protoplast swelling, and the lower reduction of plasma membrane ATPase activity that occurred in GLK-8903-treated plants during chilling appear to support this conclusion.

\section{Literature Cited}

Auffret, C.A. and D.E. Hanke. 1981. Improved preparation and assay and some characteristics of ATPase activity from Limonium vulgare. Biochem. Biophys. Acta 648:186-191.

Bates, L.S., R.P. Waldren, and E.D. Teare. 1973. Rapid determination of free proline for water-stress studies. Plant \& Soil 39:205-207.

Chu, T., M. Jusaitis, D. Aspinall, and L.G. Paleg. 1978. Accumulation of free proline at low temperature. Physiol. Plant 43:254-260.

Dhindsa, R.S. and W. Matowe. 1981. Drought tolerance in two mosses: Correlated with enzymatic defense against lipid peroxidation. J. Expt Bot. 32:79-91.

Dhindsa, R.S., P. Plumb-Dhindsa, and T.A. Thorpe. 1981. Leaf senescence: Correlated with increased levels of membrane permeability and lipid peroxidation, and decreased levels of superoxide dismutase and catalase. J. Expt. Bot. 32:93-101.

Duncan, D.R. and J.M. Widholm. 1987. Proline accumulation and its implication in cold tolerance of regenerable maize callus. Plant Physiol. 83:703-708.

Duncan, D.R. and J.M. Widholm. 1990. Proline is not the primary determinant of chilling tolerance induced by mannitol or abscisic acid in regenerable maize callus cultures. Plant Physiol. 95:1284-1287.

Fletcher, R.A. and G. Hofstra. 1988. Triazoles as potential plant protectant, p. 321. In: D. Berg and M. Plempel (eds.). Sterol biosynthesis inhibitors pharmaceutical and agricultural aspects. Ellis Hardwood, Cambridge.

Flores, A., A. Gran, F. Laurich, and K. Dorffling. 1988. Effect of new terpenoid analogues of abscisic acid on chilling and freezing resistance. J. Plant Physiol. 132:362-369.

Flores, A. and K. Dorffling. 1990. A comparative study of the effects of abscisic acid and new terpenoid abscisic acid analogues on plant physiological processes. J. Plant Growth Regulat. 9:133-139.

Flores-Nimedez, A., K. Dorffling, and B.S. Vergara. 1990a. A new phytohormone analog for preventing rice membrane injury after chilling. Intl. Rice Res. Nwslt. 15(2):19.

Flores-Nimedez, A.A., B.S. Vergara, and K. Dorffling. 1990b. Abscisic acid analog inhibits rice leafrolling caused by chilling. Intl. Rice Res. Nwslt. 15(4):20.

Fricker, M.D. and C.M. Willmer. 1987. Vanadate sensitive ATPase and phos-phatase activity in guard cell protoplasts of Commelina J. Expt Bot. 38:642-648.

Heath, R.L. and L. Packer. 1968. Photoperoxidation in isolated chloroplasts. I. Kinetics and sterolchemistry of fatty acid peroxidation. Arch. Biochem. Biophys. 125:189-198.

Lee-Stadelmann, O.Y., W.R. Bushnell, C.M. Curran, and E.J. Stadelmann. 1991. Permeability to nonelectrolyte as an indicator of change in membrane lipid structure in Hordeum vulgare cells infected by Erysiphe graminis f. sp. hordei. Physiol. \& Mol. Plant Pathol. 38:163-178.

Lyons, J.M., J.K. Raison, and P.L. Steponkus. 1979. The plant membrane in response to low temperature: An overview, p. 1-24. In: J.M. Lyons, D. Grahams, and J.K. Raison (eds.). Low temperature stress in crops plants. Academic, New York.

Mayak, S., R.L. Legge, and J.E. Thompson. 1983. Superoxide radical production by microsomal membranes from senescing carnation flowers: An effect on membrane fluidity. Phytochemistry 22:1375-1830.

Palta, J.P. and P.H. Li. 1980. Alterations in membrane transport properties by freezing injury in herbaceous plants. Evidence against rupture theory. Physiol. Plant. 50:169-175.

Palta, J.P., J. Levitt, and E.J. Stadelmann. 1977. Freezing injury in onion bulb cells. I. Evaluation of the conductivity method and analysis of ion and sugar efflux from injured cells. Plant Physiol. 60:393-397.

Rikin, A., D. Atsmon and C. Gitler. 1979. Chilling in cotton (Gassypium hirsutum L.): Prevention by abscisic acid. Plant Cell Physiol. 20:1537-1546. Stadelmann, E.J. 1966. Evaluation of turgidity, plasmolysis and deplasmolysis of plant cells, p. 143-216. In: S.M. Prescott, (ed.). Methods in cell physiology. Academic, New York

Stadelmann, E.J. and O.Y. Lee-Stadelmann. 1989. Passive permeability. Methods Enzymol. 174:246-266.

Tseng, M-J., C. Zhang, and P.H. Li. 1986. Quantitative measurements of mefluidide protection of chilled corn plants. J. Amer. Soc. Hort. Sci. 111:409-412.

Uemura, M. and S. Yoshida. 1986. Studies on freezing injury in plant cells. II. Protein and lipid changes in the plasma membranes of Jerusalem artichoke tubers during a lethal freezing in vivo. Plant Physiol. 80:187-195.

Whitaker, B.D. and C.Y. Wang. 1987. Paclobutrazol and chilling on leaf membranes in cucumber seedlings. Physiol. Plant. 70:404-411.

Wierenga, P.J. and R.M. Hagan. 1966. Effects of cold irrigation water on soil temperature and crop growth. Calif. Agr. 20:14-16.

Xin, Z. and P.H. Li. 1992. Abscisic acid-induced chilling tolerance in maize suspension cultured cells. Plant Physiol. 99:707-711.

Zhang, L.X., P.H. Li, and M.J. Tseng. 1987. Amelioration of chilling injury in rice seedlings by mefluidide. Crop Sci. 27:531-534. 